\title{
Trends of HIV Viral Load in Patients under Combined Antiretroviral Treatment in Bangui, Central African Republic
}

\author{
Yawo Tufa Nyasenu ${ }^{*}$, Alain Farra1, Serge Ghislain Djorie², Brice Martial Yambiyo², \\ Alexandre Manirakiza ${ }^{2}$, Gilles Stephane Ngaya ${ }^{1}$, Sandrine Moussa ${ }^{3}$, Pulchérie Pelembi', \\ Davy Martial Golongba', Aubin Bere', Rodolphe Mambely-Nzako1, Marie-Joëlle Mandeng1, \\ Alain Berlioz-Arthaud', Pierre-Alain Rubbo', Jean-Pierre Lombart ${ }^{1}$ \\ ${ }^{1}$ Institut Pasteur of Bangui, Medical Analysis Laboratory, Bangui, Central African Republic \\ ${ }^{2}$ Institut Pasteur of Bangui, Epidemiology Service, Bangui, Central African Republic \\ ${ }^{3}$ Institut Pasteur of Bangui, Retrovirus Service, Bangui, Central African Republic \\ Email: *nyasenu@yahoo.fr, farra_alain@yahoo.fr, djorie2000@yahoo.fr, ybricemartial@yahoo.fr, \\ alexandre.manirakiza@pasteur-bangui.org,nyages77@yahoo.fr, sandmoussa@hotmail.com, pulcherima2@yahoo.fr, \\ dmgolongba@yahoo.fr, berostau@yahoo.fr, mambely_rodolphe@yahoo.fr, mjmandeng@yahoo.fr, \\ alain.berlioz-arthaud@pasteur.fr, pierrealainrubbo@gmail.com, jean-pierre.lombart@pasteur.fr
}

How to cite this paper: Nyasenu, Y.T., Farra, A., Djorie, S.G., Yambiyo, B.M., Manirakiza, A., Ngaya, G.S., Moussa, S., Pelembi, P., Golongba, D.M., Bere, A., Mambely-Nzako, R., Mandeng, M.-J., Berlioz-Arthaud, A., Rubbo, P.-A. and Lombart, J.-P. (2018) Trends of HIV Viral Load in Patients under Combined Antiretroviral Treatment in Bangui, Central African Republic. World Journal of AIDS, 8, 53-62. https://doi.org/10.4236/wja.2018.82005

Received: May 18, 2018

Accepted: June 24, 2018

Published: June 27, 2018

Copyright (C) 2018 by authors and Scientific Research Publishing Inc. This work is licensed under the Creative Commons Attribution International License (CC BY 4.0).

http://creativecommons.org/licenses/by/4.0/ Open Access

\begin{abstract}
Background: The success of antiretroviral therapy requires better virological monitoring. We described the virological profile of patients on combined antiretroviral therapy (cART) for HIV/AIDS in Bangui, Central African Republic (CAR). Methods: In this prospective cohort study of patients who had been on combined antiretroviral therapy treatment (cART) for at least 12 months in Bangui, only one HIV plasma viral load per patient was realized at the Institut Pasteur of Bangui, between April 4th and November 28th, 2017. Sociodemographic and biological data were collected. Blood samples were taken for viral load. The biocentric generic human immunodeficiency virus (HIV) load test was used to quantify a ribonucleic acid (RNA) HIV-1. Data were analyzed with Stata software version 14. Chi-squared test was used to analyse viral load according to sex and age. The level of significance was set at $P \leq 0.05$. Results: A total of 3569 patients were recruited, with a mean age of 40 years (median, 42 years; range, 1 - 84), patients aged 40 - 49 predominating (34.2\%). The sex ratio was 0.4 . No virus was detectable in plasma from $49.2 \%$ of patients, while $42.4 \%$ had virological failure (viral load, $\geq 1000$ copies $/ \mathrm{mL}$ ) according to WHO criteria. The risk for virological failure decreased with age $(P=0.001)$ and was higher among females than males $(P=0.001)$. Conclusions: The rate of virological failure among patients on cART is very high in the CAR, despite the availability of and access to monitoring of HIV plasma viral load in Bangui. Therefore, adherence to treatment should be evaluated
\end{abstract}


and reinforced in Bangui, CAR.

\section{Keywords}

Plasma Viral Load, Failure, HIV-1, Bangui, CAR

\section{Introduction}

The Central African Republic (CAR), landlocked country has undergone a decade of socio-political instability, which has led to a humanitarian crisis and a weakening of the country's health system. The Global Fund to Fight Acquired Immunodeficiency Syndrome (AIDS), Tuberculosis and Malaria and other partners have been worked with local authorities to strengthen the health system and to address the diseases of the century, especially human immunodeficiency virus (HIV/AIDS). In 2010, the prevalence of HIV infection was $4.9 \%$ among adults aged 15 - 49 years old throughout the country and $7.7 \%$ in the capital, Bangui [1]. In 2015, the national center for monitoring internal displacement reported that 368,859 people were in informal camps [2]. In December 2015, in view of the precarity and vulnerability of the population, 18,250 patients with HIV infection received emergency stocks of 3 months of antiretroviral therapy (ART) [3], which were renewed frequently. With controling and sustaining rapidly, the multiplication of the virus decreased and immunocompetence restored.

Therapeutic success depends on close monitoring from initiation of treatment and over time. Biological and clinical follow-up after 12 months of treatment is essential to evaluate antiretroviral therapy (ART) and to detect HIV resistance [4] [5]. In 2015, the World Health Organization (WHO) recommended that the monitoring of patients on ART should include CD4 cell counts and measurement of HIV plasma viral load; virological failure was defined as a viral load $\geq 1000$ copies/mL [6] [7] [8]. In practice, the viral load is estimated from the number of copies of ribonucleic acid (RNA) HIV-1 per milliliter of plasma, determined with commercial molecular technic used to evaluate the effectiveness of ART.

In 2017, with the support of the International Federation of Red Cross and Red Crescent Societies, the Institute Pasteur of Bangui (IPB) proposed the measurement of HIV viral load and other biological tests for the monitoring of people living with HIV (PLWH) were taken in charge. The objective of this study is to describe the virological profile of patients receiving antiretroviral therapy in CAR.

\section{Patients, Materials and Methods}

\subsection{Type of Study, Duration, Inclusion or No Inclusion Criteria and Respect for Anonymity of Patients}

In this prospective cohort study of patients in Bangui, who have been on ART for at least 12 months, consisting in 1st line regimen as recommended by 
2013-revised World Health Organization (WHO) recommendations [8], only one viral load per patient was realized to IPB, during April to November 2017. The IPB is a charitable public institute working by agreement with the Government in the CAR since February 1961. The main activities of the institute are biomedical research, public health support and training. The research is oriented towards public health, providing information to the local health authorities on emerging and neglected diseases such as Buruli ulcer. It also participates in field studies during epidemics (rabies, yellow fever and arboviruses diseases such as dengue) and works with national programs, against poliomyelitis and measles. The institute has a medical analysis laboratory, which provides services for the entire population of the country, including biological monitoring of people living with HIV (PLWH). Inclusion criteria for this study were followed: antiretroviral therapy since at least 12 months, consisting in 1st line regimen as recommended by 2013-revised WHO recommendations [8]; availability of simple demographic data of patients (age, gender), treatment history (duration), informed consent from patients or tutors. We excluded from this study: HIV-infected patients who were on treatment for less than one year and patients infected with HIV-2. In this study using clinical files and electronic registers, the patient's identity was not collected in the survey file to ensure ethical clearance.

\subsection{Sample, RNA Extraction and Real-Time Polymerase Chain Reaction Amplification}

A blood sample was taken from all patients for quantification of RNA HIV-1 into a tube with ethylenediamine tetraacetic acid (EDTA), and the plasma was divided into aliquots and stored at $-20^{\circ} \mathrm{C}$ until doing RNA extraction according to manufacturer's procedures. Biocentric RNA HIV extraction kits (12.08.02 - 170,510) and automated methods using NorDiag Arrow extractor (AO637R3) have been used for HIV-RNA extraction. Biocentric RNA HIV amplification kits (TR001-250IC) was used for real-time PCR on Applied Biosystems QuantStudio ${ }^{\mathrm{Tm}} 5$ (A28133). The target region was on the long terminal repeats (LTRs), and the detection limit was 390 copies/mL. The technic is specific for $\mathrm{HIV}-1$ group of $\mathrm{M}$ sub-types $\mathrm{A}-\mathrm{H}$.

\subsection{Statistical Analysis}

Data were entered onto Excel $^{\oplus}$ sheets and analyzed with Stata software version 14. The data included the sex and age of patients, and viral load, categorized as $<300$ (virological suppression or undetectable). The viral load was presented as $<1000$ copies/mL (virological success) and $\geq 1000$ copies $/ \mathrm{mL}$ (virological failure). The World Health Organization (WHO) guidelines recommend the use of viral load as the preferred method for monitoring treatment response over clinical and immunological approaches, and define virological failure with a threshold of 1000 copies/mL [7] [8]. The analysis was performed on all data from included patients (exhaustive sampling). Chi-squared tests and odds ratios with 
95\% confidence intervals (CIs) were used to analyze viral loads according to sex and age. The level of significance was set at $P \leq 0.05$.

\section{Results}

The viral load of 3569 patients was measured during the study period. The mean age was $40 \pm 13$ years, with a range of 1 - 84; most of patients $(34.2 \%)$ were in the age range to $40-49$ years old (Table 1 ).

Table 2 shows the distribution of patients by detectable HIV viral load and undetectable HIV viral load by age group and sex. The number of patients with a detectable viral load was inversely related to age, with significant differences from those with no detectable virus in each age group. Significantly more female (51.1\%) than male patients aged 40 - 49 years has no detectable virus (Table 2).

Among the $42.4 \%$ of patients with virological failure according to $\mathrm{WHO}$ $(\geq 1000$ copies $/ \mathrm{mL}$ ), the proportions decreased with increasing age: $62.7 \%$ of those among patients aged $<18$ years, $51.1 \%$ of those among patients aged $19-29$ years, $42.7 \%$ of those among patients aged 30 - 39 years, $40.7 \%$ of those among patients aged $40-49$ and $35.1 \%$ of those among patients $>50$ years. The

Table 1. Distribution of patients by sociodemographic characteristics and HIV viral load.

\begin{tabular}{|c|c|}
\hline No. of patients & 3569 \\
\hline \multicolumn{2}{|l|}{ Age (years) } \\
\hline Mean & $40 \pm 13$ \\
\hline Median & 42 \\
\hline Range & $1-84$ \\
\hline$\leq 18$ & $295(8.27 \%)$ \\
\hline $19-29$ & $229(6.42 \%)$ \\
\hline $30-39$ & $969(27.15 \%)$ \\
\hline $40-49$ & $1220(34.18 \%)$ \\
\hline$\geq 50$ & $856(23.98 \%)$ \\
\hline \multicolumn{2}{|l|}{ Sex } \\
\hline Male & $1033(28.94 \%)$ \\
\hline Female & $2536(71.06 \%)$ \\
\hline \multicolumn{2}{|c|}{ HIV viral load (copies/mL) } \\
\hline$<300$ & $1755(49.17 \%)$ \\
\hline $300-1000$ & $302(8.46 \%)$ \\
\hline $1001-10,000$ & $842(23.59 \%)$ \\
\hline $10,001-100,000$ & $360(10.09 \%)$ \\
\hline$\geq 100,001$ & $310(8.69 \%)$ \\
\hline
\end{tabular}

Half of the patients in this study $(49.2 \%)$ has an undetectable viral load $(<300$ copies $/ \mathrm{mL})$, while the remainder $(50.8 \%)$ has a detectable viral load $\geq 300$ copies $/ \mathrm{mL}$. 
Table 2. Distribution of patients by detectable and undetectable viral load according to age group and sex.

\begin{tabular}{|c|c|c|c|c|c|c|c|}
\hline & & l load & opies/mL) & & & & \\
\hline & $\geq 300$ (detectable) & $\%$ & $<300$ (undetectable) & $\%$ & & & \\
\hline & Age group (years) & & & & & & \\
\hline$\leq 18$ & 199 & 67.46 & 96 & 32.54 & 0.001 & 0.4 & $0.3 ; 0.6$ \\
\hline $19-29$ & 130 & 56,77 & 99 & 43.23 & 0.012 & 1.5 & $1.1 ; 2.2$ \\
\hline $30-39$ & 508 & 52.43 & 461 & 47.57 & 0.001 & 1.8 & $1.4 ; 2.4$ \\
\hline $40-49$ & 608 & 49.84 & 612 & 50.16 & 0.001 & 2.0 & $1.6 ; 3.6$ \\
\hline$\geq 50$ & 369 & 43.11 & 487 & 56.89 & 0.001 & 2.7 & $2.0 ; 0.5$ \\
\hline Sex & & & & & & & \\
\hline Male & 574 & 55.57 & 459 & 44.43 & 0.001 & 0.8 & $0.7 ; 0.9$ \\
\hline Female & 1240 & 48.90 & 1296 & 51.10 & 0.001 & 1.3 & $1.1 ; 1.5$ \\
\hline Both & 1814 & 50.83 & 1755 & 49.17 & & & \\
\hline
\end{tabular}

Table 3. Distribution of patients by virological failure or success according to age group and sex.

\begin{tabular}{|c|c|c|c|c|c|c|c|}
\hline & \multicolumn{4}{|c|}{ Virological status (copies/mL) } & \multirow{2}{*}{$P$} & \multirow{2}{*}{ OR } & \multirow{2}{*}{$95 \% \mathrm{CI}$} \\
\hline & $\geq 1000$ (failure) & $\%$ & $<1000$ (success) & $\%$ & & & \\
\hline & \multicolumn{7}{|l|}{ Age group (years) } \\
\hline$\leq 18$ & 185 & 62.71 & 110 & 37.29 & 0.001 & 0.5 & $0.4 ; 0.7$ \\
\hline $19-29$ & 117 & 51.09 & 112 & 48.91 & 0.008 & 1.6 & $1.1-2.2$ \\
\hline $30-39$ & 414 & 42.72 & 555 & 57.28 & 0.001 & 2.2 & $1.7-2.9$ \\
\hline $40-49$ & 496 & 40.66 & 724 & 59.34 & 0.001 & 2.4 & $1.9-3.2$ \\
\hline$\geq 50$ & 300 & 35.05 & 556 & 64.95 & 0.001 & 3.1 & $2.3-4.1$ \\
\hline \multicolumn{8}{|l|}{ Sex } \\
\hline Male & 483 & 46.76 & 550 & 53.24 & 0.001 & 0.034 & $1.0 ; 1.2$ \\
\hline Female & 1029 & 40.58 & 1507 & 59.42 & 0.001 & 0.001 & $1.1-1.4$ \\
\hline Both & 1512 & 42.37 & 2057 & 57.63 & & & \\
\hline
\end{tabular}

More female patients (59.4\%) than male patients has undetectable HIV viral load, where as more male patients $(46.8 \%)$ has virological failure. Nevertheless, almost every other patient showed virological failure.

comparison of patients with and without virological failure by age group showed statistically significant differences (Table 3).

\section{Discussion}

We observed a preponderance of women, with a sex ratio of 0.4 , and a median age of 42 years. These results are similar to those of Mouala C et al. [9], who found a sex ratio of 0.4 and a median age of 32.5 years in a study of factors associated with adherence to treatment among HIV-infected patients in Bangui in 2006.

At a detection level of 300 copies $/ \mathrm{mL}$ of blood plasma, $49.2 \%$ of patients had 
an undetectable viral load (virological suppression). This rate is lower than those found elsewhere, such as $83.3 \%$ in Benin [10], 84\% in Morocco [11] and 96\% in the west part of the Ile de France (Paris region) [12]. The low rate in the CAR is due to the unstable sociopolitical situation in the country, which has complicated geographical access to treatment and the monitoring of patients. HIV viral load is more available and more accessible in the capital, Bangui, in view of the cost and technical requirements of the test. Samples have taken into tubes containing EDTA, which must be maintained at $4^{\circ} \mathrm{C}$ and transferred rapidly to the laboratory four hours after the collect. An alternative to this system would for regional health centres to send dried blood spots (DBS) on filter paper for analysis centrally. In this way, all the regions of the country would have access to early measurement of HIV viral load [13] [14] [15] [16] [17]. Patient's adherence to treatment could also be evaluated and strengthened in order to increase the rate. The adherence rate measured about 10 years ago in Bangui was 77.5\% [9]. Regular measurement in routine practice could increase the rate.

The fact that $42.4 \%$ of patients are virological failure could result in therapeutic failure for nearly half of all our patients. Virologic failure has often been described and associated with therapeutic failure in the country. In 2012, Pere $\mathrm{H}$ et al., according to the 2010 WHO guidelines, observed in RCA, in 386 adult patients on first-line antiretroviral treatment for 24 months, a virological failure in 28.5\% (HIV-1 RNA > $3.7 \log$ (10) or 5000 copies/ml). Twenty-four percent of patients in virological failure showed wild-type viruses, likely indicating poor adherence. Even after excluding the M184V mutation, $76 \%$ of patients in virological failure displayed viruses harboring at least one major drug resistance mutation to nucleoside reverse transcriptase inhibitors (NRTI), non-NRTI, or protease inhibitors [18]. Moussa $S$ et al., have also studied the emergence of resistance mutations in isolates from CAR patients at failure of d4T-AZT/3TC/ NVP-EFV, the resistance mutations observed are those which are expected on HIV-1 subtype B [19]. These observations point the necessity to monitor patient receiving regimen by plasma HIV-1 RNA load to diagnose situations of therapeutic failure and to operate switch. The same finding was made in children after 18 to 30 months of ARV treatment by Charpentier C et al. in 2012, who found a detectable viral load in $53 \%$ of children, $40 \%$ of whom were virologically failed (HIV-1 RNA > $3.7 \log$ (10) copies/ml) [20]. Mossoro-Kpinde CD et al. in 2016 had been found in children under 5, on first- and second-line antiretroviral therapy, who have a detectable viral load, a virological failure of 97\% [21]. With untreated young children living in the CAR, Charpentier C et al., found that $66 \%$ of them showed plasma HIV-1 > 1000 copies/ml and were in virological failure, according to the 2015 WHO guidelines [22].

Monitoring of patients is important to ensure that the treatment is effective and their health improves, and therapeutic follow-up requires measuring the viral load, which is the main biological method for identifying and confirming virological failure. If viral load cannot be measured routinely, diagnosis of therapeutic failure is based on the $\mathrm{CD} 4$ cell count and clinical follow-up, with, when 
possible, targeted measurement of viral load to confirm the diagnosis [6]. Virological failure, indicated by a viral load above the threshold of detection, should be confirmed by successive sampling and differential diagnosis of a "blip" (virological extrasystole), non-adherence or stopping treatment. The importance of the difference between the limit of detection and the threshold of 1000 copies/mL has been discussed in a number of studies. Nevertheless, the quantifiable viral load should be monitored, as low viremia can lead to virological failure and then to therapeutic failure or the emergence of mutant viruses that are resistant to ART [17] [23] [24] [25] [26] [27].

More female than male patients have an undetectable viral load (51.1\%), and more female patients (59.4\%) showed virological success, as reported elsewhere [9] [10]. The risk of female patients for a detectable viral load was significantly lower than that of male patients. Female patients adhere more closely to their treatment than male patients, as they learn the importance of adherence during perinatal visits and attend health centers more frequently, where medical personnel reinforce the message. Men have poorer adherence either because they forget, are too busy or do not wish to take their drugs. The probability of having detectable virus decreases with age. Difficult access to paediatric forms of ART and the behavior of adolescents may explain their high rate of virological failure; with age, patients are more aware of their condition and the importance of good adherence to treatment [9]. The predominance of heterosexual, vertical transmission in tropical regions, particularly in sub-Saharan Africa, may explain the prevalence of the disease in this age group [10] [28].

Sociopolitical disturbance, the distance to treatment centers, treatment with several drugs and their side-effects have all been reported to contribute to poor adherence to ART [9] [10] [29] [30]. Measurement of viral load is essential in order to diagnose the rate of therapeutic failure and to strengthen treatment adherence. In view of the situation in the CAR, some patients may have been lost to follow-up or have had to interrupt their treatment. Better access to viral load measurement could improve the management of patients on ART in the country.

The accessibility of HIV viral load is still improvable in the CAR. The limitations of this study relate to other biological parameters of the follow-up that were not sought. Immunological and hematological parameters are also determining factors in the therapeutic evaluation of patients on cART. But given the size of this study and its objective, these parameters were not studied in all patients so not reported. This study, however, updated the virological profile data for a large proportion of patients on antiretroviral therapy and described the trends in HIV viral load by age group and sex. Other studies will deepen the question of the multidisciplinary management of patients under treatment in the CAR.

\section{Conclusion}

HIV viral load is more available in Bangui. Virological failure was observed in $42.4 \%$ of patients, while $49.2 \%$ had undetectable virus. The high rate of virologi- 
cal failure associated with immunodeficiency could result in therapeutic failure. It is therefore essential to strengthen monitoring of treatment adherence and improve access to measurement of viral load in Bangui, CAR.

\section{Acknowledgements}

We thank the Ministry of Public Health, Population and the Fight against AIDS, the Global Fund to Fight AIDS, Tuberculosis and Malaria, the International Federation of Red Cross and Red Crescent Societies, the Pasteur Institute of Bangui and the people living with HIV who participated in the study. We acknowledge Elisabeth Heseltine for her technical assistance.

\section{Financial Support}

This material is the result of work supported with resources from and the use of facilities at the Pasteur Institute of Bangui (IPB).

\section{Potential Conflicts of Interest}

All authors declare that they have no interests in respect of the subject of this manuscript.

\section{References}

[1] Central African Institute for Statistics and Economic and Social Studies (2010) Multiple Indicator Cluster Surveys.

[2] Centre de surveillance des déplacements internes (2015). http://www.internal-displacement.org/

[3] International Federation of Red Cross and Red Crescent Societies. Central African Republic: A Difficult Operational Context-Success Story. https://media.ifrc.org/ifrc/

[4] Mellors, J.W., Munoz, A., Glori, J.V., Margolick, J.B., Tassoni, C.I., Gupta, P., et al. (1997) Plasma Viral Load and CD4+ Lymphocytes as Prognostic Markers of HIV-1 Infection. Annals of Internal Medicine, 126, 946-954. https://doi.org/10.7326/0003-4819-126-12-199706150-00003

[5] Hammer, S.M., Saag, M.S., Schechter, M., Montaner, J.S., Schooley, R.T., Jacobsen, D.M., et al. (2006) Treatment for Adult HIV Infection: 2006 Recommendations of the International AIDS Society-USA Panel. JAMA, 296, 827-843. https://doi.org/10.1001/jama.296.7.827

[6] WHO (2017) Information Note: Management of HIV (WHO/VIH/2017.22). Geneva. http://www.who.int/hiv/en/

[7] WHO (2016) Consolidated Guidelines on the Use of Antiretroviral Drugs for Treating and Preventing HIV Infection: Recommendations for a Public Health Approach. 2nd Edition, Geneva.

[8] WHO (2013) Consolidated Guidelines on the Use of Antiretroviral Drugs for Treating and Preventing HIV Infection: Recommendations for a Public Health Approach. Geneva.

[9] Mouala, C., Kaba-Mebri, J., Wata, J.B. and Rey, J.L. (2006) Facteurs associés à une bonne observance thérapeutique chez les patients infectés par le VIH à Bangui. Cahiers détudes et de recherches francophones/Santé, 16, 119-130. 
[10] Lozès, E., Ahoussinou, C., Agassounou-Tchibozo Djikpo, M., Dahouegnon, E., Ahossouhe, N., Acoty, A. and de Souza, C. (2012) Variabilité du taux des lymphocytes CD4 et de la charge virale chez les personnes vivant avec le VIH sous traitement antiretroviral: Cas de l'hopital Saint Jean De Dieu de Tanguieta (Benin). International Journal of Biological and Chemical Sciences, 6, 650-656. https://doi.org/10.4314/ijbcs.v6i2.9

[11] Marchand, C., Himmich, H., Maaroufi, A., Sohier, N., Chambon, J.-F. and Gagnayre, R. (2005) Mise en oeuvre et évaluation d'un programme d'éducation thérapeutique (2000-2001) pour les patients atteints du VIH à Casablanca (Maroc). Cahiers détudes et de recherches francophones/Santé, 15, 73-80.

[12] Flexor, G., Zucman, D., Berthé, H., Meier, F., Force, G., Greder-Belan, A., et al. (2013) Vieillissement et infection par le VIH: Suivi de 149 patients âgés de plus de 60 ans infectés par le VIH (COREVIH Île-de-France Ouest [Ageing and HIV infection: 4 Years' Follow-Up of 149 HIV-Infected Patients Older than 60 years in West Paris Agglomeration (COREVIH Île-de-France Ouest). La Presse Médicale, 42, e145-e152. https://doi.org/10.1016/j.lpm.2012.11.005

[13] Amellal, B., Katlama, C. and Calvez, V. (2007) Evaluation of the Use of Dried Spots and of Different Storage Conditions of Plasma for HIV-1 RNA Quantification. HIV Medicine, 8, 396-400. https://doi.org/10.1111/j.1468-1293.2007.00484.x

[14] Brambilla, D., Jennings, C., Aldrovandi, G., Bremer, J., Comeau, A.M., Cassol, S.A., et al. (2003) Multicenter Evaluation of Use of Dried Blood and Plasma Spot Specimens in Quantitative Assays for Human Immunodeficiency Virus RNA: Measurement, Precision, and RNA Stability. Journal of Clinical Microbiology, 41, 1888-1893. https://doi.org/10.1128/JCM.41.5.1888-1893.2003

[15] Cassol, S.A., Gill, M.J., Pilon, R., Cormier, M., Voigt, R.F., Willoughby, B., et al. (1997) Quantification of Human Immunodeficiency Virus Type 1 RNA from Dried Plasma Spots Collected on Filter Paper. Journal of Clinical Microbiology, 35, 2795-2801.

[16] Kane, C.T., Ndiaye, H.D., Diallo, S., Ndiaye, S., Wade, A.S., Diaw, P.A., et al. (2008) Quantitation of HIV-1 RNA in Dried Blood Spots by the Real-Time NucliSENS EasyQ HIV-1 Assay in Senegal. Journal of Virological Methods, 148, 291-295. https://doi.org/10.1016/j.jviromet.2007.11.011

[17] Mwaba, P., Cassol, S., Nunn, A., Pilon, R., Chintu, C., Janes, M., et al. (2003) Whole Blood Versus Plasma Spots for Measurement of HIV-1 Viral Load in HIV Infected African Patients. The Lancet, 362, 2067-2068. https://doi.org/10.1016/S0140-6736(03)15103-3

[18] Péré, H., Charpentier, C., Mbelesso, P., Dandy, M., Matta, M., Moussa, S., De Dieu Longo, J., Grésenguet, G., Abraham, B. and Bélec, L. (2012) Virological Response and Resistance Profiles after 24 Months of First-Line Antiretroviral Treatment in Adults Living in Bangui, Central African Republic. AIDS Research and Human Retroviruses, 28, 315-323. https://doi.org/10.1089/aid.2011.0127

[19] Moussa, S., Pinson, P., Pelembi, P., Gody, J.C., Mbitikon, O., Fikouma, V., Mbay, P. and Fleury, H.J. (2010) First Data on HIV-1 Resistance Mutations to Antiretroviral Drugs in Central African Republic. AIDS Research and Human Retroviruses, 26, 1247-1248. https://doi.org/10.1089/aid.2010.0091

[20] Charpentier, C., Gody, J.C., Mbitikon, O., Moussa, S., Matta, M., Péré, H., Fournier, J., Longo, J.D.D. and Bélec, L. (2012) Virological Response and Resistance Profiles after 18 to 30 Months of First- or Second-/Third-Line Antiretroviral Treatment: A Cross-Sectional Evaluation in HIV Type 1-Infected Children Living in the Central African Republic. AIDS Research and Human Retroviruses, 28, 87-94. 
https://doi.org/10.1089/aid.2011.0035

[21] Mossoro-Kpinde, C.D., Gody, J.C., Mboumba Bouassa, R.S., Mbitikon, O., Jenabian, M.A., Robin, L., Matta, M., Zeitouni, K., Longo, J.D., Costiniuk, C., Grésenguet, G., Touré Kane, N.C. and Bélec, L. (2017) High Levels of Virological Failure with Major Genotypic Resistance Mutations in HIV-1-Infected Children after 5 Years of Care according to WHO-Recommended 1st-Line and 2nd-Line Antiretroviral Regimens in the Central African Republic: A Cross-Sectional Study. Medicine, 96, e6282. https://doi.org/10.1097/MD.0000000000006282

[22] Charpentier, C., Gody, J.C., Tisserand, P., Matta, M., Péré, H., Fournier, J., Mbitikon, O. and Bélec, L.(2011) Surveillance of Antiretroviral Drug Resistance Mutations in Untreated Young Children Living in the Central African Republic. Antiviral Therapy, 16, 1347-1350. https://doi.org/10.3851/IMP1896

[23] Ellman, T.M., Alemayehu, B., Abrams, E.J., Arpadi, S., Howard, A.A. and El-Sadr, W.M. (2017) Selecting a Viral Load Threshold for Routine Monitoring in Resource-Limited Settings: Optimizing Individual Health and Population Impact. Journal of the International AIDS Society, 20, e25007. https://doi.org/10.1002/jia2.25007

[24] Panel on Antiretroviral Guidelines for Adults and Adolescents (2016) Guidelines for the Use of Antiretroviral Agents in HIV-1 Infected Adults and Adolescents. Department of Health and Human Services, Rockville.

[25] Havir, D.V., Bassett, R., Leviatan, D., Gilbert, P., Tebas, P., Collier, A.C., et al. (2001) Prevalence and Predictive Value of Intermittent Viremia with Combination HIV Therapy. JAMA, 286, 171-179. https://doi.org/10.1001/jama.286.2.171

[26] Rycavage, P., Kelly, S., Li, J.Z., Harrigan, P.R. and Taiwo, B. (2014) Significance and Clinical Management of Persistent Low-Level Viremia and Very-Low-Level Viremia in HIV-1-Infected Patients. Antimicrobial Agents and Chemotherapy, 58, 3585-3598. https://doi.org/10.1128/AAC.00076-14

[27] Taiwo, B., Gallien, S., Aga, E., Ribaudo, H., Haubrich, R., Kuritzkes, D., et al. (2001) Antiretroviral Drug Resistance in HIV-1-Infected Patients Experiencing Persistent Low-Level Viremia during First-Line Therapy. The Journal of Infectious Diseases, 204, 515-520. https://doi.org/10.1093/infdis/jir353

[28] Aubry, P. (2012) Infection à VIH/SIDA et tropiques, actualités. In: Cours de Médecine Tropicale: Pathologie Infectieuse et Tropicale.

http://www.medecinetropicale.com/

[29] Kebede, A. and Tajure, W.N. (2012) Medication Adherence and Its Determinants among Patients on Concomitant Tuberculosis and Antiretroviral Therapy in South West Ethiopia. North American Journal of Medical Sciences, 4, 67-71. https://doi.org/10.4103/1947-2714.93376

[30] Potchoo, Y., Tchamdja, K., Balogou, A., Pitche, V.P., Guissou, I.P. and Kassang, E.K. (2010) Knowledge and Adherence to Antiretroviral Therapy among Adult People Living with HIV/AIDS Treated in the Health Care Centers of the Association "Espoir Vie Togo" in Togo, West Africa. BMC Clinical Pharmacology, 10, 11. https://doi.org/10.1186/1472-6904-10-11 